\title{
2D-QSAR Studies of Dopamine Transporter Inhibitors (DAT) Using OPS and GA Variable Selection Approaches ${ }^{\dagger}$
}

\author{
Eduardo Borges de Melo 1', Aline Thais Bruni 2,3 and João Paulo Ataide Martins 4,* \\ 1 Laboratório de Química Medicinal e Ambiental Teórica (LQMAT), UNIOESTE, Campus Cascavel, \\ PR. CCMF/Rua Universitária, 2069, Cascavel PR 85819-110, Brazil; eduardo.b.de.melo@gmail.com \\ 2 Departamento de Química, FFCLRP, USP/RP, Av. Bandeirantes, 3900, Ribeirão Preto SP 14040-901, Brazil; \\ aline.bruni@usp.br \\ 3 Instituto Nacional de Ciência e Tecnologia Forense (INCT Forense), Ribeirão Preto SP 14040-901, Brazil \\ 4 Departamento de Química - Instituto de Ciências Exatas (DQ-ICEx), Av. Antônio Carlos 6627, \\ Belo Horizonte MG 31270-090, Brazil \\ * Correspondence: joaopauloam@gmail.com \\ + Presented at the 2nd Molecules Medicinal Chemistry Symposium (MMCS): Facing Novel Challenges in \\ Drug Discovery, Barcelona, Spain, 15-17 May 2019.
}

Published: 4 December 2019

\begin{abstract}
Today, drug abuse has developed into a social problem and begun to demand specific measures from different social sectors and government agencies all over the world. Despite significant efforts made toward relevant mechanistic targets, such as the dopamine transporter (DAT), the development of pharmacotherapeutic treatments of psychostimulant abuse has remained a challenge so far. Using a set of 49 2-[(diphenylmethyl)sulfanyl]ethanamines described as DAT inhibitors, 2D-QSAR/PLS studies were performed using two different approaches of variable selection: Ordered predictors selection (OPS) and genetic algorithm (GA). All structures were optimized at the B3LYP/6-311G++(d,p) level of theory. The molecular descriptors were obtained in the Dragon 6 program (topological, geometric, molecular, and constitutional) and GaussView 03 (electronic). Both models were formed by two latent variables. Model 1 (OPS) was constructed with four molecular descriptors (GATS3m, Mor15p, SpMin3_Bh(s), and HOMO-1), while six (Mor13m, CATS2D_09_LL, RDF110u, RDF085m, Mor24s, and RDF010s) were required to obtain model 2 (GA). The models can be considered reasonably different: In model 1, electronic features predominate, whereas in model 2 , steric and geometric effects do. The overall test indicated that models 1 and 2 have equivalent predictive ability (Average $r^{2} \mathrm{~m}$ Overall $=0.730$ versus 0.710 and Delta $r^{2}$ Overall $=0.122$ versus 0.151 ). However, model 1 is simpler (it has only four descriptors, which facilitates its interpretation), presents more relevant information used in the construction of its two latent variables $(75.99 \%$ versus $64.07 \%)$, and its calibration is more significant than that of model 2 $\left(F_{n, n-p-1}=115.814\right.$ versus 80.888 , for the same tabled $F$ value, where $n=36$, and $n-p-1=3.256$, with alfa $=0.05$ ). Considering these results, although model 2 may also be considered a good result, model 1, obtained using the OPS approach for variable selection, may be considered more reliable for prediction purposes. This result is in agreement with good results previously obtained using the OPS methodology.
\end{abstract}

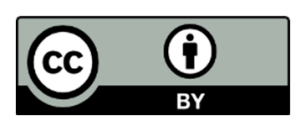

(C) 2019 by the authors. Licensee MDPI, Basel, Switzerland. This article is an open access article distributed under the terms and conditions of the Creative Commons Attribution (CC BY) license (http://creativecommons.org/licenses/by/4.0/). 